\title{
Isolation and identification of the microbial strains from the dental plaque in the patients with fixed dental appliances - preliminary study
}

\author{
Cristina Nicoleta $\mathrm{MIHAI}^{1}$, Gabriel $\mathrm{CIOCHINDA}^{1}$, Claudia Camelia BURCEA ${ }^{1}$, \\ Mihai BURLIBASA ${ }^{1}$, Viorel Stefan PERIEANU ${ }^{1}$, Madalina Violeta PERIEANU ${ }^{1}$, Oana EFTENE ${ }^{1}$, \\ Iuliana BABIUC ${ }^{1}$, Ruxandra STANESCU ${ }^{1}$, Olivia POPOVICIU ${ }^{1}$, Madalina MALITA ${ }^{1}$, Radu COSTEA ${ }^{1}$, \\ Magdalena Natalia DINA ${ }^{1}$, Oana-Cella ANDREI ${ }^{1}$, Liliana BURLIBASA ${ }^{2}$, Ileana IONESCU ${ }^{1}$ \\ 1"Carol Davila" University of Medicine and Pharmacy Bucharest, Romania \\ ${ }^{2}$ Faculty of Biology, University of Bucharest, Romania
}

\section{ABSTRACT}

Introduction. A special role in the occurrence of acute or chronic infections is the microbial biofilms, which contain several microbial species and which develop mainly on inert surfaces.

Purpose. The objective of this research is to obtain scientific information on microbial biofilms relevant to human health, in order to identify and improve the prophylactic and therapeutic methods of the infections caused by them.

Material and method. This research focuses on the study of the microbial plaque attached to the dental surfaces, from patients wearing fixed dental appliances. The study was performed on a number of 39 patients wearing fixed orthodontic appliances.

Results and discussion. Several types of microbial strains have been identified - Burkholderia cepacia, Pseudomonas aeruginosa, Serratia liquefaciens, Enterobacter cloacae, Eikenella corodens, Lactobacillus sp., Bacteroides sp., Candida albicans etc.

Conclusion. The identification of the microbial strains isolated from the dental plaque revealed a great diversity of the aerobic and aerobic facultative anaerobic microbial species, which supports the hypothesis of the nonspecific bacterial plaque, involved in the etiology of periodontal diseases.
\end{abstract}

Keywords: fixed dental appliances, dental microbial plaque, microbial biofilm

\section{INTRODUCTION}

Since ancient times, the human race has been the victim of infectious diseases with an out of the ordinary aggressivity, these diseases being produced in most cases by bacterial species that live either on or in the human body or in the environment. In fact, we can say that many of these bac- 
terial species can cause infections of extreme gravity, especially in patients who already have serious health problems (here we discuss, in particular, about the immune-compromised patients) (1-5).

However, a particular role in the occurrence of this type of acute or chronic infections, but with variable severity, are the microbial biofilms, which contain several microbial species and which mainly develop on inert surfaces (1-5).

\section{PURPOSE}

Basically, through inert surfaces, at this point we can discuss both about dead tissues, but also medical devices: contact lenses (over time various strains of Pseudomonas aeruginosa, gram-negative cocci etc.), venous catheters (Staphylococcus epidermidis etc.), mechanical valves (Staphylococcus epidermidis, S. aureus etc.), endotracheal tubes (various bacteria and fungi) etc. (1-5).

Regarding the devices and the medical instruments used in the current dental practice, we should mention the intermediate prosthetic pieces such as occlusion rims and complete dentures wax try in, classic fixed and mobile prosthetic restorations, but also implant supported prosthetic restorations. It must also include a multitude of devices and tools specific to the specialists in orthodontics and dentofacial orthopedics: mobile orthodontic appliances, orthodontic rings, brackets or other attachments for soldering, arches, ligatures, but also orthodontic instruments from pliers category [loop forming pliers, ring and/or bracket removing pliers, ligature archwire cutter or distal end cutters, ligature tying pliers (Steiner pliers, Coon pliers, Mathieu orthodontic pliers, orthodontic Mosquito forceps) and so on (1-5).

But, when we talk about these microbial biofilms that we find in fixed orthodontic appliances, we have to keep in mind that, they are mainly found in children and adolescents, but, nowadays, we find more and more fixed orthodontic appliances among adults (1-5).

The purpose of this study, even if it is preliminary one, is to obtain scientific information on microbial biofilms in patients with fixed dental appliances. In fact, we discuss about the establishment of a bacterial strain and fungal from the dental microbial plaque, the most important microbial biofilm in the oral cavity, from patients wearing fixed dental appliances (1-5).

\section{MATERIAL AND METHOD}

Before proceeding to the actual implementation of the study, some extremely brief clarifica- tions are required, both on some basics notions, but also on the specialized terminology of orthodontics and dentofacial orthopedics.

Thus, the fixed dental appliances is a special construction, which is applied to the vestibular or oral (lingual) surface of the teeth. This type of orthodontic appliance can be physiognomic (made of ceramic and sapphire) or non-physiognomic (made of metal alloys). The fixed dental appliance is an orthodontic device made of brackets, rings and archwire (6). It is an assembly of elements that are fastened, glued, or clamped on teeth. It may contain some additional components, depending on the complexity of the treatment and the teeth problems. As a general principle of use, the fixed orthodontic appliance consists of a multitude of small brackets that stick to the surface of the teeth, being joined by means of archwire. For molars, the classic treatment uses cemented metal rings, but the doctor can also use attached tubes, similar to the brackets, this technique reducing the patient's discomfort and facilitating access to those areas, for the hygienic purposes (both for self-cleaning and professional hygiene performed by the orthodontic specialist (6).

Basically, the establishment of this base of bacterial and fungal strains consists in the collection of dental microbial plaque from above and below gingival margin, from a group of patients carrying fixed dental appliances, who have camed in several offices with orthodontic and dentofacial orthopedic profiles with a private character from Bucharest, for specialized controls, which in most cases included professional scaling and brushing.

We are actually discussing about 39 patients, children, adolescents and adults with fixed dental appliances, between the ages of 10 and 39, who showed up in profile dental offices, where a large part of the authors work. The study was conducted between $15^{\text {th }}$ May and $30^{\text {th }}$ May 2019. The age distribution of the patients included in this study group was as follows (Fig. 1):

- Age range 10-20 years: 19 subjects, representing $48.72 \%$;

- Age range 20-30 years: 14 subjects, representing 35.90\%;

- Age range 30-39 years: 6 subjects, representing $15.38 \%$.

Regarding gender distribution of the study group, 23 of the subjects were female and the rest of 16 subjects were male.

In order to carry out the process of collecting dental microbial plaque, the informed consent of the patients was obtained if they were adults, or of their parents, if they were minors. The entire 


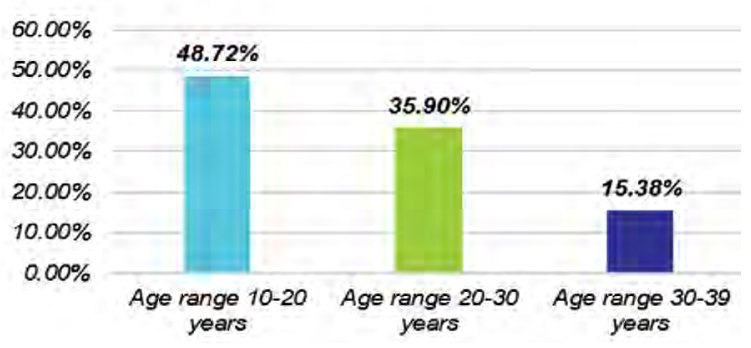

FIGURE 1. Age distribution of subjects involved in the study

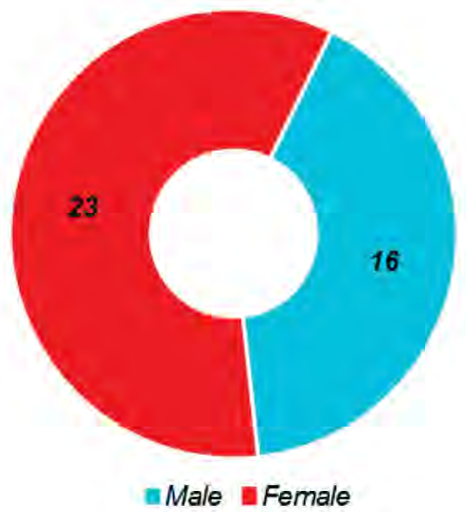

FIGURE 2. Gender distribution of patients involved in the study

study was conducted anonymously. Although each patient had the opportunity to withdraw at any time during the study, no subject expressed this desire.

Dental microbial plaque harvesting was performed, with common consulting instruments used in the current dental practice (dental explorer probe, dental tweezers, dental mirror, to which Heidemann spatula was added), as well as the manual dental scaling instruments (claw type tartar scaler, cisel scalers, sickle scalers, hoe scalers, as well as various types of curettes, where was the case). Most of these maneuvers for the collection of supra- and subgingival plaque were performed under local anesthesia by applying lidocaine spray.

This process of collecting microbial dental plaque was performed before performing the procedures of professional scaling and brushing. All the collected samples were placed in phosphate buffered saline suspensions and transported to the microbiology laboratory with which we collaborated. We recall that all patients were carriers of fixed dental appliances (7-10).

\section{RESULTS AND DISCUSSIONS}

In the first stage, the isolation of the microbial strains from the supra- and subgingival dental plaque samples took place. Basically, from the ini- tial sample (suspended in phosphate buffered saline), the primary isolation media were seeded, represented by blood agar and YPG medium (Yeast Extract-Peptone-Glycerol), were incubated at a temperature of $35-37^{\circ} \mathrm{C}$, for a period of time of 24-48 hours, to allow the development of slow-growing germs. From the culture obtained for 24-48 hours, Gram smears were created to highlight the morphological types.

Samples collected from the dental microbial plaque were then seeded on non-selective enriched media (blood agar) and incubated at $37^{\circ} \mathrm{C}$. Culture characteristics and cell morphology were determined by analyzing the size, synthesized pigments, shape, colony development mode, as well as determining the Gram character, which allowed the classification of the isolated strains, according to the tinctorial affinity and the morphological type. At the same time, depending on the morphotinctorial characteristics and the results of rapid enzymatic tests for oxidase and catalase, the types of API galleries were selected, in order to identify with certainty the respective strains.

As already mentioned, the certainty identification of the microbial strains is done by establishing the biochemical profile using the API (Analytical Profile Index) tests. The BioMérieux API tests are micro-test systems, used for the biochemical identification of microbial strains. The microtest galleries were inoculated, incubated and interpreted, according to the manufacturer's instructions. In this study, the galleries API Staph, API 20 Strep, API $20 \mathrm{~A}, \mathrm{API}$ 20E, API 20NE were used.

API Staph is a standardized system for identifying species belonging to the genera Staphylococcus, Micrococcus and Kocuria. API Staph galleries consist of 20 microtubes, containing dehydrated substrates. These microtubes are inoculated with a bacterial suspension prepared in API Staph medium. During incubation, following the metabolism of the biochemical substrates, color changes occur that are either spontaneous or highlighted by the subsequent addition of reagents. An incubation box is prepared (tray and lid) and distribute approximately $5 \mathrm{ml}$ of distilled, demineralized or any water without additives or chemical compounds, which can produce gases (e.g. $\mathrm{Cl} 2, \mathrm{CO} 2$ etc.) in the wells alveolar of the tray, to create a moist atmosphere. With the help of a pipettes or PSIpettes fill the microtubes with API Staph medium inoculated only in the tube portion of the microtubes, not in the wells; anaerobic conditions are ensured in the wells of the ADH and URE tests, by filling the wells with mineral oil. The bacterial suspension used to inoculate the tube with API 
Staph medium is a homogeneous bacterial suspension, with turbidity equivalent to 0.5 McFarland standard from a pure culture of a species of family Micrococcaceae (membership verified by determining morphology, Gram staining, catalase). After the incubation period (18-24 h, at $360^{\circ} \mathrm{C} \pm 20^{\circ} \mathrm{C}$ ), the gallery is read, and various reagents are added to visualize the reactions, as indicated in the leaflet.

API 20 Strep is a standardized system, which combines 20 biochemical tests with high differentiation power, which allow group or species identification of most Streptococcus and Enterococcus, or species of other microorganisms related to them. API 20 Strep gallery contains 20 microtubes with dehydrated substrates, for highlighting enzyme activity or sugar fermentation. Enzyme assays are inoculated with a dense bacterial suspension, with turbidity greater than 4 McFarland. The microtubes in the first half of the gallery are filled (VP to ADH tests), for the VP to LAP tests, about $100 \mu \mathrm{l}$ is distributed in each well, and for the ADH test only the tube is filled. In the second half of the gallery (RIB tests up to GLYG), transfer the remaining suspension from the API Suspension Medium vial is transfered to a vial of API GP Medium and distribute this new suspension only in the test tubes. For the tests from ADH to GLYG, the tubes and wells test are filled with mineral oil, until a convex meniscus forms, and the incubation box is placed at a temperature of $360^{\circ} \mathrm{C} \pm 20^{\circ} \mathrm{C}$ under aerobic conditions, for a period of time of approximately 4-41/2 hours for a first reading and about 24 hours ( \pm 2 hours) for the second reading, if necessary.

API 20A offers the possibility of easy and rapid identification of anaerobic bacteria, with the help of 21 biochemical tests. The gallery is seeded with a suspension with a turbidity greater than or equal to at least 3 McFarland made in API 20A medium; for the GEL test both the tube and the well are filled, and for the IND test only the tube with API 20A medium and the well with mineral oil are filled to facilitate the accumulation of the volatile indole. The incubation box is left for a period of approximately 24 hours ( \pm 2 hours) at a temperature of $360^{\circ} \mathrm{C} \pm 20^{\circ} \mathrm{C}$, under anaerobic conditions. The reading is done according to the Reading Table.

Thus, the identification of the microbial strains isolated from the dental plaque revealed a great diversity of aerobic and facultative anaerobic microbial species, represented by: Burkholderia cepacia, Pseudomonas aeruginosa, Serratia liquefaciens, Enterobacter cloacae, Eikenella corodens,
Lactobacillus sp., Bactobacillida sp. albicans etc. Basically, the presence of these microbial strains supports the hypothesis of the nonspecific bacterial plaque, involved in the etiology of periodontal diseases.

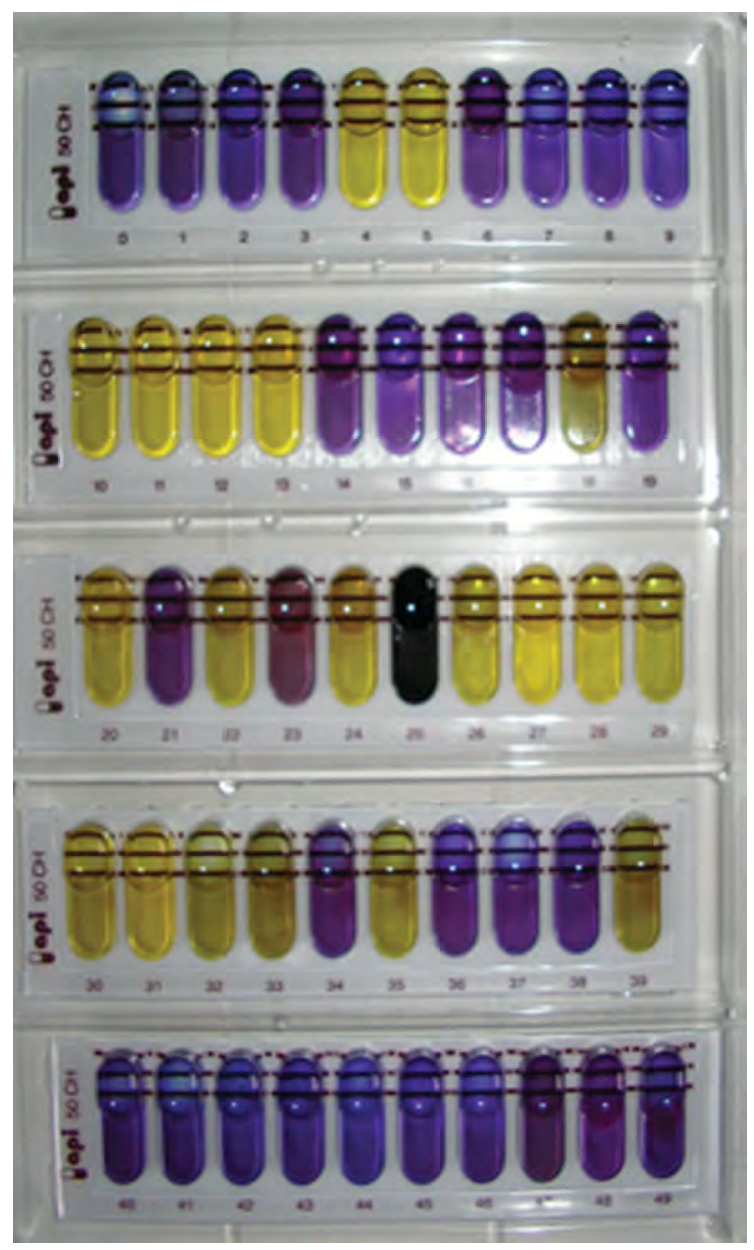

FIGURE 3. Examples of the biochemical tests, obtained with the help of microtest galleries type API (Lactobacillus sp.)

But, practically it is known that the oral cavity offers a unique habitat for many bacterial species, being colonized with one of the most diverse microbiome existing in the unsterile cavities of the human body, consisting of approximately 600-800 bacterial species. So far, the cultivation of 200-300 species from the human oral cavity has been successful and about 400 other phylotypes have been detected, using a variety of analytical methods independent of their cultivation. Of the approximately 700 possible colonizers, it is estimated that between 100 and 200 species are constantly present in a healthy individual.

Thus, the isolated and then identified microbial strains in our study support the nonspecific bacterial plaque hypothesis, implicated in the etiology of periodontal diseases. However, these microbial strains are even among the species that initially 
colonize the dental surfaces, due to the ability to adhere directly to the salivary film and represent $60-90 \%$ of the bacteria that colonize the teeth, even in the first 4 hours after their professional cleaning.

\section{CONCLUSIONS}

All the patients involved in the study showed a great deal of understanding and patience regarding the collection of dental microbial plaque samples, even if these maneuvers were sometimes painful, although the harvesting was done under the action of the anesthetic spray Lidocain.

The creation of this base of microbial strains isolated from the supra- and subgingival dental microbial plaque from patients wearing fixed dental appliances was achieved due to well-established schedules, strictly respected by both patients and by medical staff. No significant difficulties were encountered during the harvest, but also during the transport of the samples collected to the microbiology laboratory with which we collaborated.
Although a large number of supra- and subgingival dental microbial plaque samples were collected, this aspect allowed us a very rigorous selection of isolated and identified microorganisms. Basically, this isolation and identification of microorganisms in the dental microbial plaque was in full agreement with the information available in the specialized literature.

Microbiology studies were conducted with very high accuracy and conscientiousness, the results obtained being in accordance with the studied profile materials.

Isolated microbial strains support the nonspecific bacterial plaque hypothesis, implicated in the etiology of periodontal disease.

Isolated microbial strains are among the species that colonize the dental surfaces, probably also the components of fixed dental appliances, including brackets.

\section{Acknowledgement}

In this article, all the authors have equal contribution with the first author.

Conflict of interest: none declared Financial support: none declared

\section{REFERENCES}

1. Burlibaşa M. Iniţierea, dezvoltarea şi combaterea biofilmelor microbiene formate pe suprafaţa materialelor de amprentă în reabilitarea implanto-protetică. Bucureşti: Ed. Cermaprint, 2008.

2. Bilinschi LG, Burlibaşa M, Burlibaşa L et al. Studiul interacţiunii dintre biofilmele microbiene şi materiale de amprentare utilizate în protetica dentară. În: Burlibaşa M, Bilinschi LG, Costea R et al. Probleme în medicină şi biologie, Vol. VIII. Bucureşti: Ed. Ars Docendi, 2018: 23-109.

3. Lazăr V. Aderenţa microbiană. Bucureşti: Ed. Academiei Române, 2003.

4. Burlibaşa M, lonescu I, Bodnar DC et al. Aspecte teoretice şi practice ale formării, dezvoltării şi combaterea biofilmelor microbiene în medicina dentară. Revista Medicina Modernă. 2008; 15(10): 544-547.

5. Nolte AW. Oral Microbiology with Basic Microbiology and Immunology $4^{\text {th }}$ Edition. St. Louis: CV Mosby Company, 1982.

6. Dentarbre. [Interactiv] [Citat: 2111 2019.] https://www.dentarbre.com/blog/aparatulortodontic-fix-calea-spre-zambetstralucitor/.

7. Lazăr V, Cernat R, Balotescu C. Microbiologie generală. Manual de lucrări practice. Bucureşti: Ed. Universităţii din Bucureşti, 2004.

8. Biomerieux. $A P^{\circledR}$ Staph (25 strips +25 media) ref 20500. [Interactiv] [Citat: 2111 2019.] https://biomerieuxdirect.com/ industry/Bacteriology/ID-AST-Manual/API/
ID-Manual/Api-galleries-Staphylococci/ API\%26reg-STAPH-\%2825STRIPS\%2B25 MEDIA $\% 29 / p / 20500$

9. Biomerieux. $A P I \circledast 20$ Strep, ref 20600. [Interactiv] [Citat: 2111 2019.] https:// biomerieuxdirect.com/industry/Bacteriology/ ID-AST-Manual/ID-AST-API/ID-Manual/ Api-galleries-Streptococci/API\%26reg-20STREP-\%2825STRIPS\%2B25MEDIA\%29 $/ p / 20600$

10. Biomerieux. API 20A, ref 20300. [Interactiv] [Citat: 2111 2019.] https://biomerieuxdirect. com/industry/Bacteriology/ID-AST-Manual/ ID-AST-API/ID-Manual/Api-galleriesAnaerobes/API\%26reg-20A-\%2825STRIPS $\% 2 B 25 M E D I A \% 29 / p / 20300$ 